\title{
Frontiers in care: a case of compulsory treatment in AIDS dementia. Case study and commentaries
}

Roger Higgs and Anthony J Pinching Guy's, King's and St Thomas' School of Medicine, King's College London, and St Bartholomew's and The Royal London School of Medicine and Dentistry, University of London

\begin{abstract}
A patient with AIDS dementia was confronted and compulsorily prevented from flying out of the country before being admitted against his will to hospital.

While finding this on balance justified in the circumstances the commentators raise moral questions about the levels of care in general practice and within the couple's own relationships.

(Fournal of Medical Ethics 2000;26:61-65)

Keywords: AIDS dementia; competence; compulsion;
\end{abstract} confidentiality; promise keeping; relationships

\section{Case study}

Peter was a much-travelled university administrator of 38, who after a long period of uncertainty had finally declared himself by setting up house with Marvin. Marvin had left school at 16 and worked as a painter and decorator, but under Peter's influence and with his help was on the way to achieving an ambition to study electronics at university by doing an access course at the age of 27. They had been living together as partners for nearly two years when Peter began to act eccentrically. He was inappropriately emotional, forgetful where he had been meticulous and began to make expansive plans. He developed an unusual rash and a cough, and looked unwell. He would not agree to see a doctor.

Marvin visited a gay drop-in centre after watching a programme on AIDS, and the discussion appeared to confirm his worst suspicions that Peter was probably suffering from an HIV-related dementia, but urgently needed investigation and treatment to save his life. Before he could take any action, he found air tickets on Peter's desk indicating that he was planning to go to Moscow for an indefinite period, and that he had a valid visa and appeared to have his bags packed. The ticket was for the following day. In desperation the next morning, having been unable to confront Peter he broke down in his tutorial and asked for his tutor's help. He was afraid that Peter was ill from AIDS and that once in Russia, where he could speak the language fluently, he would disappear and perhaps die without treatment.

Uncertain what the response might be from Peter's own doctor, the tutor rang the airport authority medical service. He felt that he would not be listened to unless the message was clear, so he stated to them that he had information from a partner that Peter was travelling when ill and possibly had AIDS dementia. The airport medical services identified Peter to prevent him boarding the plane. He became very confused and there was a fight. In order to control the situation the authorities decided to use a mental health section to admit him to hospital. After two weeks, Peter was persuaded to accept transfer on a voluntary basis to an infectious disease unit but remained very angry with Marvin and their relationship deteriorated.

The episode became known to the university authorities who appeared to be making moves to discharge him from his position before union intervention.

\section{Commentary by Anthony J Pinching}

This case study is all too familiar. It highlights some of the ethical tensions that arise in clinical practice for individuals and professionals when mental health is affected by HIV. Several boundaries, and the problems of identifying and crossing them, are apparent.

HIV encephalopathy may emerge quite insidiously, and its initial features may represent plausible exaggerations of prior personality traits. The boundary between the freedom to make personal choices, even if they seem misguided, and that which represents hypomania for example, can trouble clinicians and lay observers alike. For professionals, the issue is to assess whether the patient is competent or whether there is a need to exercise a section under the Mental Health Act, whereby a person's freedoms are constrained temporarily, pending treatment. For the partner or family, the situation can be both confusing and frightening, 
especially where doctors and the police seem to take a surprisingly distant stance - because of the boundaries to what they can do.

The changes in Peter will have been apparent to Marvin before anyone else, because of the closeness of the relationship. Yet he would have been inhibited in what he could do, and would have felt very ambivalent about challenging Peter's competence to act freely, just because of the boundaries of the relationship. The situation would have been more problematic because of the balance of influence between the two individuals in the relationship, with Marvin seeming to have a degree of dependency.

The situation appears to have been compounded in this case because of the lack of a trusting relationship with the general practitioner (GP), for several possible reasons. Firstly, patients may feel ambivalent about approaching their GPs where there is concern about mental health; Peter himself may have lacked the insight into his own needs to agree to see the doctor initially. Secondly, many gay people have concerns about how they will be received by the GP (or "family doctor"). In some cases, this is because of prior bad experience of prejudice or discomfort with GPs or their staff, in others because of a fear of this. Finally, when the crisis was at its height, Marvin may have felt uncertain about whether he could, as a gay partner, speak about Peter's situation to a doctor he may never have met.

This is a critical breakdown at the core of services for patients - who should or could act in a crisis? Primary care is the key entry point for medical issues and, without uninhibited entry, patients and those close to them may be unable to access help. While others, such as social workers, can play a part in mental health crises, few members of the public know that. First access to any system will be very much affected by image and public perception, however misguided. We have seen during the HIV epidemic how essential it is to work with gay men and with GPs to rebuild this key relationship; in some cases it has taken years. The effects of perceived barriers are all too evident in this case.

It is interesting to see how the tutor came to act as agent for Marvin in the community, in turn alerting health professionals. Here was a person that Marvin knew and trusted and who would know what to do. He too felt unable to approach the GP, perhaps because he picked up on Marvin's concerns. His action in approaching the airport medical service was quite shrewd. He was thus able to speak to people with medical insights and training, but whose responsibilities include safeguarding travellers. By the very direct way in which he provided information, the need for action was unambiguous. It may be considered that he breached confidentiality, but he had no primary duty of confidentiality to Peter. He will have gathered from Marvin that there was a duty to warn, whether for Peter's best interests or indeed those of others should Peter's behaviour become disruptive during the flight.

However, if it had been a GP taking such action, then even without a duty to warn that overrode patient confidentiality, the professional-toprofessional dialogue may be construed as appropriate. The person responsible for Peter's health in the community and those responsible for his health in the air (analogous to the role of the occupational physician) could have discussed his health needs and the action to be taken, without widening the release of health information. The fact that he probably had HIV and had a cough could also have raised the issue of possible pulmonary tuberculosis, which would have justified keeping him off the flight on public health grounds.

Peter's initial detention under the Mental Health Act appears to have been a short term section relating to the incident at the airport as much as the need to detain him for his underlying state. The removal of his freedom in order to give him initial treatment for his mental health needs provided a valuable safeguard and breathing space in a situation that was escalating. However, even without the incident, there may have been a need to detain Peter under a section if he was unable to recognise the necessity for immediate treatment.

During his first two weeks' treatment, his mental health seems to have stabilised enough for him to be moved to an infectious diseases ward and to continue to receive treatment on a voluntary basis. While this may in part have resulted from drug therapy, it would have been possible, over time, to explain his situation and how he could be treated, and above all to establish trust.

It is evidently preferable to be able to treat patients on a voluntary basis. However, HIV encephalopathy leading to psychiatric disorder presents some particular problems about boundaries, regarding what the section permits. Strictly defined, the imposed treatment is solely for the proximate cause of incompetence and mental derangement; some have interpreted this as limiting involuntary drug treatment to psychotropic agents. While this may have been sufficient here, in many cases this organic brain disorder may be more readily controlled in both the short and longer term by combining these with antiretroviral therapy for the underlying disease especially including zidovudine - which can lead 
to significant functional improvement. It can be appropriate to use zidovudine as direct therapy for HIV encephalopathy, even where a patient has previously not wished to use antiretroviral drugs to prevent immunological deterioration. If Peter had needed to continue to be sectioned, these issues would have arisen. If his cough had turned out to be due to tuberculosis (TB), then his treatment for that could have been required as part of statutory tuberculosis control.

It is troubling to hear that Peter's employers, the university, seem to have considered dismissing him. Their actions were evidently based on hearsay, but even if they were correctly informed, it is moot as to whether they were motivated by concern about HIV infection, his sexuality, encephalopathy or psychiatric disorder. Such experiences are, sadly, all too common, and employers may be quite disingenuous about how and why they proceed; the unwary employee may feel, and indeed be, very vulnerable.

Evidently his employers would have had no legitimate concern about HIV infection in his role as an administrator. If they had heard that he had a brain disorder affecting his cognitive functioning or his mental health, they would have had a legitimate concern about whether it would affect his work. However, the proper way to proceed would have been to ask him to see an occupational physician to assess his health status in respect of his work. The occupational physician would see the patient in his/her role as the patient's doctor at work, in medical confidence. Formal specialist assessment could have been sought on, for example, cognitive function or psychiatric fitness. This would have included reports from the treating clinicians, with the patient's permission. If the patient was still under section and not competent, these discussions would have had to be deferred until he was able to participate; there would have been no urgency in most instances. The employers would only [need to] be told by the occupational physician what, if any, impact on employment the health issue would have. With current therapies, a patient with HIV encephalopathy may recover functioning sufficiently to be able to resume work in such a setting, though the need for medical oversight from his own physician and from occupational health would be a proper safeguard.

The impact of these events, and in particular of Marvin's actions to safeguard Peter's health, evidently affected the relationship and its structure. This is inevitable and, in the long run, could even have been beneficial. However, experience has shown that such experiences may critically unbalance relationships. In some cases, they may eventually lead to relationships breaking up.
While some of the personal difficulties that arose in this case were unavoidable, it is clear that some problems could have been made more manageable by ensuring fluent and uninhibited access to health care. At many junctures, ethical tensions arose because of important boundaries of responsibility and action. Yet it is interesting to note that, though difficult, there was nothing intrinsic to the situation that could not be resolved through existing systems and ethical practice. Unfortunately, these systems may not be known, and in complex and rapidly developing situations, especially where mental health becomes impaired, either they may not be accessed, or they may simply fail because human beings are thrown off balance by the urgency and the distress of the circumstances.

\section{Commentary by Roger Higgs}

Although at one level simply a potentially tragic story about serious communicable disease, at another level this account lays bare some of the moral issues at the heart of the promises which people make to each other. Medical ethics goes hand in hand with personal and corporate responsibilities. Peter and Marvin had formed a partnership: what did that mean they owed each other? Peter had a doctor: what did that relationship promise and what could it and should it have delivered? Marvin and Peter had vital but different links with the university: what should it have offered to students and staff? The airline was faced by a choice between serving a passenger and saving the general public. Perhaps the drop-in centre too could have seen its work on the same spectrum, albeit at a different intensity. In each of these relationships we can discern the playing out of a line of action which was linked to fundamental questions about the history, purpose and quality of that relationship. The values held or promised at least in part determined the priorities.

At the centre of this story lies the love between Peter and Marvin. Of the beauty and depth of that we can only guess. But we can discern outlines of what each gave the other in practical terms. Peter supplied stability, career direction and fulfilment for Marvin, who would traditionally be described as an under-achiever. The account given ("under Peter's influence") suggests that some of this direction by Peter may have been paternalistic, perhaps even patronising or controlling. Whether this is true or not it underlines the inequalities at this point in their relationship. Peter was welltravelled, clever, a man of the world with a steady and prestigious job: Marvin was, as yet, none of these things. But at the same time Marvin was anything but a puppet: in return he had also offered Peter stability as well as love, and a chance 
for Peter to come out and be true to himself by no longer making a secret of his homosexuality. Marvin cared desperately for Peter, and was prepared to take considerable social risks on his behalf.

Whether this love was unconditional or whether Marvin's care was fully reciprocated is hard to tell, but Peter did not offer everything which might be expected of one partner in a model modern partnership. We have no idea what their sexual rules (or roles) were, and when and where Peter acquired his infection-it could have been on his travels before he met or became committed to Marvin. But if he had not been able to be good, he sadly had not been able to be careful either. If Peter needed the risk of an affair, and had thereby taken a chance on an infection, he need not also have risked Marvin's health. The question in the case remains unposed as to whether Marvin too is now infected, or whether he wishes to find out; and whether he had any choice about this or knowledge of Peter's past. Unless they had a totally "open" partnership or were both committed to risky behaviour, Peter's refusal to see a doctor suggests that he knew he might be ill (and that his disease might be serious) but was ashamed or afraid - or both. We are all familiar with friends or relatives who just won't do the "right thing" when it comes to looking after their own health. Everyone has a different threshold for professional consultation. Such a consultation, with its potential to undermine our tranquillity, is a very mixed blessing. Many people prefer to live with subliminal worries rather than to face them openly. The blade of risk may cut both ways - being found to be ill, with all the potential consequences, or depending on the slim chance that it will solve itself and all go away. But Peter's action, or lack of it, suggests another force was at work. Perhaps he was guilty and was afraid of the consequences for his relationship with Marvin as well as for himself in facing up to the truth about his health. Even when confronted with signs of the disease which alerted his partner, he refused to seek medical help.

Was this the action of an autonomous man? Was he a free agent making a (rational) choice, and fully responsible for it, or was his mind already clouded and suspicious? There is often a point in this type of debate where everyday moral thinking parts company with the law or formal medical ethics. Anxiety, shame or confusion perhaps had already made him less than his own person. We see him, in ordinary terms, as having at least an excuse, if not a diminished responsibility in law. And if he were, in this ordinary way, not properly himself, what action could Marvin have justifiably taken? Should he have forced Peter to go to the doctor's? Should his love have refused to take no for an answer?
Even if Peter had been clear-sighted, what about the professional response he could have expected to receive? Why didn't he get a response from any primary care doctor, whether in general practice or a genitourinary clinic? In their defence it should be said that few services could be set up to take a pro-active approach to potential patients who at the time give no indication of wanting help. Only with the very vulnerable, at extremes of age for instance, would society see it as appropriate for a clinician to descend unasked and unannounced on anyone, and even so consent would be needed for any intervention. Only in cases where third parties are at risk could this be justified, assuming the person was sane. Only when Peter was clearly mentally ill and endangering himself and others could the British law take away his free choice, in this case, of not wishing to be a patient.

No doctor was approached until the airport services were alerted, so no doctor could be said to have failed in his or her duty of care. And yet, and yet. The narrative suggests that Peter had not made a good relationship with his doctor-why was that? Marvin certainly did not appear to have had a doctor of his own to turn to. The university tutor's uncertainty may have just been ignorance about services or reticence about butting in inappropriately. But all this put together suggests that the local primary care service did not offer a spectacularly open door. If they did it had not been well publicised. If Marvin and Peter had approached them before, it sounds as if they had not left with a very high opinion of what was being offered. The ideal service would be welcoming, and secure about the realities of patient confidentiality.

Was the drop-in centre better? Certainly in one sense, that it was approachable and information was to be had. But why was the opportunity for follow-up or support not there? Marvin did not feel able to go back there for help the next day. Even if it were an "evenings only" service, it should have had a policy which could have prepared it for action. This does underline the difficulties facing any agency which puts a high value on client autonomy, and adopts a counselling style. At any point, the seriousness of the situation may dictate that non-directive positive regard may have to be dropped in favour of taking decisive action to help somebody.

The university tutor luckily had no such scruples. Experience elsewhere suggests that in this regard Marvin was lucky. When institutions are under pressure and under-funded, the first thing usually to go is the pastoral aspect, or the kindness and caring which marks the difference between what people can reasonably expect and 
what they actually hope to receive. But, however satisfactory the outcome, was the tutor right to intervene? Had Peter been mildly unwell, in his right mind and fit to travel, a call like this to the airport would have been a gross intrusion or worse. But these are not the facts of the case as we have them. What the tutor saw fit to say (and the airline to hear) was not primarily about infectiousness, diagnosis or immune status but about his mental state and his fitness to fly. Peter's confusion was a threat to the safety of the passengers and crew. So the danger defined the decision. As one of the judgments in the Tarasoff case in California famously declared, " (the) protective privilege ends where the public peril begins".

But Peter could have been unfit to fly without being of sufficient danger to merit the Mental Health Act being invoked. The fight at the airport suggests that the staff were high- or heavy-handed, or that he was indeed very disturbed; and the section was justified. Here is another promise. In the United Kingdom society promises through this act to protect you against the effects of your own actions if you are suffering from a mental illness and a danger to yourself and others. Society will prevent you coming to harm even if you plan to harm others in this state. There is a move to restrict this only to situations were there is a threat of harm to others. If Peter had been peacefully confused, at least to the point that a disturbance on the flight was unlikely, this might have persuaded the authorities to let him fly.

But those thus restrained are not always grateful. Peter, by the end of the case account, is still angry with Marvin. This seems to the outsider to be very unfair. Perhaps Peter even in his confusion actually wanted to escape, either to die, or just to lose contact with the relationship and its responsibilities. Perhaps he could not face up to the realities of his own disease and what he had done. Perhaps he was angry with Marvin as surrogate for the system which had taken away his liberty. But perhaps he now sees that his own position in his personal relationship has changed. It is now Marvin who is the powerful one, by being (though for how long?) physically well, by being decisive, and now by being in control. The anger certainly suggests that their relationship is going through difficulties. Perhaps it was not strong enough to deal with the terrible issues at stake. Perhaps their relationship was not deep enough to allow them to discuss the issues as they first arose.

So while we are not satisfied with the failed link between Peter and his doctor, were this link to have been made should we have expected this relation- ship to have taken its cue from Peter's other relationships? Should we expect a doctor to try to develop more open communication with Peter about sensitive personal matters than Peter could establish within his own partnership with Marvin? There seems some sense in questioning this, since a closer professional-client than client-partner relationship could possibly create further tensions as the former threatens the latter and competition or jealousy arises. Alastair Campbell has suggested that professional caring relationships can be seen as a form of moderated love ${ }^{2}$ : even if they remain professional, they might risk harm if they were more intense than those in the client's personal life. Yet it is sadly common for life partners to have inhibited, rather than facilitated, their communication about difficult feelings. Marvin was unable to confront Peter, even when he was obviously ill. It rings lots of bells. But it would have made no sense for the professional (in this case the tutor) to refuse to handle the situation because the couple could not handle it themselves. A professional's approach would be to try to help unblock the silted-up channels of communication, and support the partners while difficult things were being said. A promise like that would be a promise indeed. This painful episode could then have been prevented before Peter got ill. But once Peter's life was in danger, or he was endangering others, the imperative in medical ethics to prevent or minimise further harm becomes overwhelming, even if Peter's own autonomous decisions are overridden. How that should be done again should minimise the destructive effects of paternalistic action. The principle of respect for Peter's autonomy remains, even if trumped for the time being by other considerations. Trust with doctors has to be restored. Without that, Peter cannot improve. Without that, the deeper process of restoration of his own relationship with Marvin is unlikely to begin.

Roger Higgs is Professor of General Practice and Primary Care, King's College London, Weston Education Centre, 10, Cutcombe Road, London SE5 9RF. Anthony $\mathcal{F}$ Pinching is Louis Freedman Professor of Immunology and Fellow, Department of Human Science and Medical Ethics, St Bartholomew's and The Royal London School of Medicine and Dentistry, Queen Mary \& Westfield College, West Smithfield London EC1A $7 B E$.

\section{References}

1 Beauchamp TL, Walters L. Contemporary issues in bioethics. Belmont California: Wadsworth, 1994:174-8

2 Campbell AV. Moderated love. London: SPCK, 1984. 